\title{
Gut Vagal Afferents Are Not Necessary for the Eating-Stimulatory Effect of Intraperitoneally Injected Ghrelin in the Rat
}

\author{
Myrtha Arnold, ${ }^{1}$ Anna Mura, ${ }^{1}$ Wolfgang Langhans, ${ }^{1}$ and Nori Geary ${ }^{1,2}$ \\ ${ }^{1}$ Institute of Animal Sciences, Swiss Federal Institute of Technology Zurich, Schwerzenbach 8603, Switzerland, and ${ }^{2}$ Department of Psychiatry, Weill \\ Medical College of Cornell University, New York, New York 10032
}

Ghrelin is unique among gut peptides in that its plasma level increases during fasts and its administration stimulates eating. Although ghrelin physiology has been intensively studied, whether its eating-stimulatory effect arises from endocrine-neural signal transduction at peripheral or central sites remains unresolved. To address this issue, we tested the effects of subdiaphragmatic vagal deafferentation (SDA), the most complete and selective vagal deafferentation method available, on ghrelin-induced eating. SDA was verified with a cholecystokinin satiation test, retrograde labeling of vagal motor neurons in the dorsal motor nucleus of the vagus with fluorogold, and anterograde labeling of vagal afferents in the nucleus tractus solitarius with wheat germ agglutinin-horseradish peroxidase. Intraperitoneal injections of $10-40 \mu \mathrm{g} / \mathrm{kg}$ ghrelin stimulated eating as robustly in rats with verified complete SDA as in sham-operated controls. Ghrelin also stimulated eating in rats with total subdiaphragmatic vagotomies. We also recorded the electrophysiological responses of gastric load-sensitive vagal afferent neurons to intravenous ghrelin. Ghrelin $(10 \mathrm{nmol})$ phasically $(0-30 \mathrm{~s})$ increased activity in two of seven gastric load-sensitive fibers in the absence of gastric loads and tonically (5-30 min) increased activity in only one fiber. Ghrelin did not affect any of the eight fibers tested in the presence of 1-3 ml gastric loads. We conclude that although phasic increases in plasma ghrelin may affect the activity of a fraction of gastric load-sensitive vagal afferents, the acute eating-stimulatory effect of intraperitoneal ghrelin does not require vagal afferent signaling.

Key words: food intake; obesity; vagus; electrophysiology; hunger; gastric mechanoreceptors

\section{Introduction}

The gastric peptide ghrelin, discovered in 1999 (Kojima et al., 1999) as an endogenous ligand for the growth hormone secretogogue receptor type 1a (GHS-R1a) (Howard et al., 1996), is perhaps best known for its "hunger" effect (for review, see Geary, 2004; van der Lely et al., 2004; Kojima and Kangawa, 2005; Williams and Cummings, 2005). In animals and humans, fasting increases and eating inhibits ghrelin secretion, and ghrelin administration stimulates eating. In humans, subjective hunger ratings track changes in plasma ghrelin levels (Wren et al., 2001b; Schmid et al., 2005). Furthermore, peripheral and central administration of antibodies against ghrelin or of GHS-R1a antagonists inhibit eating in rats and mice (Nakazato et al., 2001; Murakami et al., 2002; Asakawa et al., 2003; Bagnasco et al., 2003).

Originally, ghrelin was supposed to increase food intake by acting in the hypothalamic arcuate nucleus (Arc) on the grounds that GHS-R1a is present there and that ghrelin administered directly into the Arc stimulated eating (Wren et al., 2001a; Bagnasco et al., 2003; Cowley et al., 2003). However, ghrelin admin-

Received June 21, 2006; revised Sept. 1, 2006; accepted Sept. 1, 2006

We thank Dr. Gary Schwartz for demonstrating the electrophysiological techniques and Dr. Lori Asarian for assistance with data imaging and statistical analyses.

Correspondence should be addressed to Dr. Nori Geary, Institute of Animal Sciences, Swiss Federal Institute of Technology Zurich, Schwerzenbach 8603, Switzerland. E-mail: nori-geary@ethz.ch.

DOI:10.1523/JNEUROSCI.2606-06.2006

Copyright $\odot 2006$ Society for Neuroscience ～0270-6474/06/2611052-09\$15.00/0 istration into other brain sites, including the hypothalamic paraventricular nucleus (PVN) (Wren et al., 2001a; Olszewski et al., 2003; Currie et al., 2005), the ventral tegmental area (VTA) (Naleid et al., 2005), and the dorsal vagal complex (DVC) (Faulconbridge et al., 2003), also stimulated eating. In addition, GHS-R1a mRNA is present in numerous other brain sites in which the effects of ghrelin administration have not been tested (Zigman et al., 2006). GHS-R1a is also present on vagal afferents (Date et al., 2002), and several data suggest ghrelin stimulates eating via a vagally mediated abdominal action. Total subdiaphragmatic vagotomy (TVX), selective gastric vagotomy, or perivagal capsaicin injection blocked the eating-stimulatory effect of intravenous ghrelin in rats (Date et al., 2002, 2005), and TVX blocked the eating-stimulatory effect of intraperitoneal (IP) ghrelin in mice (Asakawa et al., 2001). Finally, intravenous ghrelin infusion failed to increase eating in humans after TVX and lower esophageal or gastric surgery (le Roux et al., 2005). Also consistent with vagal mediation of the eating-stimulatory effect of ghrelin, ghrelin decreased vagal afferent activity in rats (Asakawa et al., 2001; Date et al., 2002, 2005), and its effects on eating, gastric vagal activity, and c-Fos expression in the nucleus tractus solitarius were each antagonized by coadministration of cholecystokinin (CCK) (Date et al., 2005; Kobelt et al., 2005), which signals satiation via vagal afferents (Smith et al., 1981, 1985; Moran et al., 1997; Geary, 2004).

To further test the hypothesis that vagal afferents mediate the acute eating-stimulatory effect of ghrelin, we investigated the ef- 
fects of IP ghrelin injection in rats with subdiaphragmatic vagal deafferentation (SDA) (Norgren and Smith, 1994; Walls et al., 1995; Schwartz et al., 1997), the most selective method available to disconnect abdominal vagal afferents. Because SDA failed to block the eating-stimulatory effect of ghrelin, we retested the effects of IP ghrelin in rats with TVX. Finally, we recorded the responses of gastric load-sensitive vagal afferents to intravenous ghrelin or CCK. None of the results supports the hypothesis that vagal afferents mediate the acute eating-stimulatory effect of IP ghrelin.

Preliminary reports of some of the data were given at the Annual Meeting of the Society for the Study of Ingestive Behavior (Mura et al., 2004) and at the 34th Annual Meeting of the Society for Neuroscience (Arnold et al., 2004).

\section{Materials and Methods \\ Animals}

Male Sprague Dawley rats (Charles River, Sulzfeld, Germany) were individually housed in stainless-steel drawer cages with grated floors. The colony room was maintained at $22 \pm 2 \mathrm{C}^{\circ}$ and $60 \%$ humidity, with a $12 \mathrm{~h}$ light/dark cycle (lights on from 5:00 A.M. to 5:00 P.M.). Rats were given water and standard ground rodent diet ad libitum (Provimi Kliba Nafag, Kaiseraugst, Switzerland) unless otherwise noted. All experimental protocols were approved by the Veterinary Office of the Canton of Zurich.

\section{SDA experiments}

Surgery. The effects of SDA on the eating-stimulatory effect of IP ghrelin were tested in two sets of rats, which differed only in the ghrelin doses tested and in the method used to verify the surgery. In series 1, 25 rats [body weight (BW), 240-300 g] were operated: 12 received SDA, 12 received sham deafferentation (SHsda), and one died in surgery. In series 2, 58 rats (BW, $240-280 \mathrm{~g}$ ) were operated: 29 received SDA, 18 received SHsda, 4 received intentionally partial unilateral vagal rhizotomy to assist us in the verification, and 6 died in surgery.

SDA consisted of left-side intracranial vagal rhizotomy and transection of the dorsal (left) subdiaphragmatic trunk of the vagus (see TVX below), resulting in complete subdiaphragmatic vagal deafferentation (Norgren and Smith, 1994). SHsda consisted of similarly exposing the vagal rootlets and dorsal subdiaphragmatic vagus but not further manipulating them. Intentional partial SDA consisted of attempting to perform a left vagal rhizotomy that was only $\sim 40-80 \%$ complete. Rats were pretreated with IP injections of $50 \mu \mathrm{g} / \mathrm{kg}$ atropine (Sintetica; Mendrisio, Bern, Switzerland) and $80 \mu \mathrm{g} / \mathrm{kg}$ azepromazine (Prequillan; Arovet AG, Zollikon, Switzerland) and then anesthetized $15 \mathrm{~min}$ later by IP injection of a mixture of $80 \mathrm{mg} / \mathrm{kg}$ ketamine (Narketan; Vetóquinol AG, Bern, Switzerland), $4 \mathrm{mg} / \mathrm{kg}$ xylazine (Rompun; Bayer AG, Leverkusen, Germany) in $1.1 \mathrm{ml} / \mathrm{kg}$ saline. Supplemental injections of ketamine were given as required. Body temperature was maintained at $37-38^{\circ} \mathrm{C}$ throughout surgery with a $39^{\circ} \mathrm{C}$ water pad. Five milliliters of warm saline were injected intraperitoneally after closing the abdomen, a combination of trimethoprim and sulfadoxine (90 $\mu \mathrm{l} / \mathrm{rat}$ Borgal 7.5\%; Intervet, Boxmeer, The Netherlands) was injected subcutaneously immediately after surgery for infection prophylaxis, and $5 \mathrm{mg} / \mathrm{kg}$ carprofen (Rimadyl; E. Gräub AG, Bern, Switzerland) was injected subcutaneously after surgery and on each of the following $2 \mathrm{~d}$ for analgesia. Surgery was done with sterile technique. Rats were offered access to a familiar milk diet (35\% condensed milk in water; Migros, Zurich, Switzerland) for 1 week after surgery to facilitate recovery. Body weight recovered to the preoperative level within $5 \mathrm{~d}$ and did not differ significantly between SDA and SHsda thereafter. Rats were thoroughly adapted to handling and IP injections until this no longer visibly aroused them or elicited feeding.

Ghrelin-induced eating. The acute effects of peripheral ghrelin on food intake were tested in SDA and SHsda rats $\sim 6$ weeks after surgery, when the rats that were subsequently verified to have complete SDA weighed $376 \pm 8$ and $426 \pm 9 \mathrm{~g}$ in series 1 and 2, respectively, and SHsda rats weighed $403 \pm 8$ and $441 \pm 6 \mathrm{~g}$. Food cups were weighed, and spill papers were placed beneath the cages between 7:00 and 8:00 A.M., ghrelin (rat ghrelin, molecular weight, 3315 g; Bachem, Bubendorf, Switzerland) or the vehicle ( $1 \mathrm{ml} / \mathrm{kg} 0.15 \mathrm{M}$ saline) was intraperitoneally injected at 9:30-
10:30 A.M., and food intake was measured 30, 60, and 120 min later. In series 1 , the effects of IP injection of 10,20 , and $40 \mu \mathrm{g} / \mathrm{kg}$ ghrelin versus vehicle injection were each tested in separate crossover tests. These three tests were done in descending dose order, with one nontest day intervening between the two trials of each crossover test and 4-7 d between crossovers. In series 2, each rat received a crossover test of $40 \mu \mathrm{g} / \mathrm{kg}$ ghrelin versus vehicle, with $1 \mathrm{~d}$ intervening between the two trials. Pilot tests indicated that $40 \mu \mathrm{g} / \mathrm{kg}$ ghrelin produced a maximal stimulation of food intake at these times under our conditions.

Verification of SDA. Functional and histological tests were used to verify the completeness of SDA. The functional test was lack of CCK satiation, which depends on abdominal vagal afferent fibers (Smith et al., 1985; Walls et al., 1995; Moran et al., 1997). Rats were food deprived for $4 \mathrm{~h}$ before intraperitoneally injecting them with $4 \mu \mathrm{g} / \mathrm{kg}$ CCK- 8 (Bachem) and returning food just before dark onset. Food intake was measured $30 \mathrm{~min}$ later. In SHsda rats, CCK-8 inhibited $30 \mathrm{~min}$ food intake $64 \pm 6 \%$ in series 1 and $46 \pm 8 \%$ in series 2 . Therefore, the inclusion criterion for SDA rats was that their reduction in $30 \mathrm{~min}$ food intake be $<30 \%$; if this was not the case, the SDA was considered incomplete, and the rat's data were not included in the data analysis.

Two histological tests of vagotomy were based on published techniques for retrograde labeling of vagal motor neurons in the dorsal motor nucleus of the vagus (DMX) and anterograde labeling of vagal afferents in the nucleus of the solitary tract (NTS) (Powley et al., 1987; Norgren and Smith, 1988; Walls et al., 1995). Each rat was intraperitoneally injected with $2 \mathrm{mg}$ of fluorogold (Fluorochrome, Denver, CO) in $1 \mathrm{ml}$ of saline. In series 2 , rats were reanesthetized $2 \mathrm{~d}$ later, the left nodose ganglion was exposed via a ventral midline neck incision, a glass micropipette was inserted into the ganglion parallel to the axis of the nerve using a micromanipulator, $1.5 \mu \mathrm{l}$ of $2 \%$ wheat germ agglutinin-horseradish peroxidase (HRP; Vector Laboratories, Burlingame, CA) in saline was pressure injected (PicoSpritzer 3; Parker Instrumentation, Fairfield, NJ) over 5-8 min, the wound was closed, and the rat was treated postoperatively as before. Two days later, rats were intraperitoneally injected with $100 \mathrm{mg} / \mathrm{kg}$ sodium pentobarbital (Nembutal; Abbott Laboratories, Abbott Park, IL) and then transcardially perfused with saline followed by $4 \%$ phosphate-buffered paraformaldehyde. Brains were removed and cryoprotected for $2 \mathrm{~d}$ in $25 \%$ sucrose in $0.1 \mathrm{~m}$ phosphate buffer at $4^{\circ} \mathrm{C}$ until serial $40 \mu \mathrm{m}$ coronal sections of the medulla were cut. One set of every fourth section was mounted onto gelatin-coated slides and air dried. An observer blind to the rat's surgery and data then counted the number of flourogold-labeled neurons in the left and right DMX in all sections that included the area postrema [(AP) this region of the brainstem is richly innervated by both motor and sensory fibers from all the branches of the abdominal vagus (Norgren and Smith, 1988)]. In series 1, the inclusion criterion for SDA rats, based on that of Phillips et al. (2000), was that the total number of labeled cells found in the right DMX was $<3 \%$ of the number found in the left DMX; if this was not the case, the SDA was considered incomplete and the rat's data were not included in the data analysis. In addition, in series 2 , another set of every fourth section was collected into ice-cold phosphate buffer, processed for HRP according to the method of Gibson et al. (1984) and digitally imaged with a dark-field microscope. An observer blind to the rat's surgery and data examined the left and right NTS in all sections that included the AP. The inclusion criteria for SDA rats, based on the work of Hamilton and Norgren (1984), Norgren and Smith (1988, 1994), and Walls et al. (1995), was that the left DMX contains some retrograde labeling as a positive control for the injection and tissue processing and that neither the left nor the right NTS contain any labeled fibers. If any labeling was detected in the NTS, the rat was considered to have an incomplete SDA, and its data were not included in the analysis.

Data analysis. Food intake data after 30 and 60 min were analyzed with a two-factor ANOVA, with surgical group (verified SDA, SHsda) a between-subjects factor and treatment (control, ghrelin) a withinsubjects factor, using Sigmastat for Windows (version 2.03; SPSS, Cary, NC). Separate ANOVAs were done for each crossover test because preliminary analyses indicated that intakes after the vehicle injections differed among the tests (e.g., in series 1, for both 30 and 60 min control intakes, the interaction of test and surgical group was significant, 
$F_{(2,38)}=3.485 .79 ; p$ values $<0.05$ and 0.01 , respectively). Significant effects were followed up using the Bonferroni-Holm method (Holm, 1979). To increase the power to detect any difference in the effect of ghrelin between SHsda and SDA rats, only three differences were tested post hoc: the ghrelin - vehicle effect in each surgical group and the difference between these differences [i.e., (SHsda ghrelin - SHsda vehicle) vs (SDA ghrelin - SDA vehicle)]. In series 2 , food intake data after 120 min deviated significantly from normality (Kolmogorov-Smirnov distance statistic, $0.177 ; p<0.001$ ), so were analyzed nonparametrically, using Wilcoxon tests for within-subjects tests of the effects of ghrelin in each surgical group and a Mann-Whitney test to compare the ghrelin saline differences between groups. Data are reported as mean \pm SEM.

\section{TVX experiments}

Surgery. Twenty five rats were operated; 16 received TVX (BW, 375$420 \mathrm{~g}$ ) and 9 received sham vagotomy (SHtvx; BW, 295-350 g). Because TVX is typically followed by a syndrome that includes hypophagia and BW loss (Kraly et al., 1986), rats of different ages were used for the two surgical groups to minimize differences in BW at testing. Starting $10 \mathrm{~d}$ before surgery, rats were given access to three palatable liquid diets (the milk diet described above plus Oranol multivitamin mix, Bayer AG; vanilla Ensure Plus, Abbott AG, Baar, Switzerland; and vanilla Clinutren, Nestlé, Vevey, Switzerland), one or two at a time for 2-3 d each and were adapted to decreasing amounts of chow until $2 \mathrm{~d}$ before surgery, when no chow was offered. General surgical and postoperative procedures were as described above. TVX was done as described previously (Smith et al., 1981; Le Sauter and Geary, 1990); briefly, after a midline laparotomy, $\sim 3$ $\mathrm{mm}$ each of the ventral (right) and the dorsal (left) esophageal vagal trunks was ligated with $4 / 0$ silk and removed. The ventral trunk was disconnected rostral to the bifurcation point of the hepatic and accessory celiac branches, and the dorsal trunk was disconnected rostral to the bifurcation point of the main celiac branches. SHtvx consisted of exposing, but not further manipulating, the vagal trunks. After surgery, rats were offered only the liquid diets and were nursed intensively. Those showing signs of dehydration were subcutaneously injected with $\sim 20$ $\mathrm{ml} / \mathrm{d}$ warm saline or saline until recovery. As expected, TVX rats lost $\sim 50 \mathrm{~g}$ in the $10 \mathrm{~d}$ after surgery, but then most stabilized and slowly increased to normal levels of food intake and rates of BW gain by $\sim 3$ weeks after surgery. Four rats died in surgery, and three rats that did not respond to supportive care were killed. Food intake tests began 2.5-3 weeks after surgery.

Ghrelin-induced eating. The acute effects of peripheral ghrelin were tested as described above. The nine SHtvx rats weighed $389 \pm 10 \mathrm{~g}$ and the nine TVX rats weighed $363 \pm 30 \mathrm{~g}$ on the first day of testing, a nonsignificant difference.

Verification of TVX. Completeness of TVX was assessed with the CCK test and with retrograde labeling of vagal motor neurons in the DMX, using the methods described above. CCK-8 inhibited $30 \mathrm{~min}$ food intake $49 \pm$ $11 \%$, so the inclusion criterion for TVX rats was again that the reduction in $30 \mathrm{~min}$ food intake be $<30 \%$. For the fluorogold test, the inclusion criterion for TVX rats was that there were less than a total of four labeled cells in both right and left DMX. The data were analyzed with ANOVA as above.

Vagal electrophysiology. The activity of single vagal gastric loadsensitive afferents was recorded using the method of Schwartz and his colleagues (Schwartz et al., 1991, 1993; Mathis et al., 1998). Rats (350$400 \mathrm{~g}$ ) were anesthetized with ketamine and xylazine as done previously and placed in a supine position with the head gently clamped in place. Body temperature was monitored by a rectal thermal probe and was maintained at $36-37^{\circ} \mathrm{C}$ by a warm-water heating pad. A $5 \mathrm{~cm}$ midline laparotomy was done and the duodenum ligated with a $3 \mathrm{~mm} \times 4 \mathrm{~cm}$ strip of latex (cut from an examination glove) just distal to the pylorus. Then, a $3 \mathrm{~cm}$ ventral midline incision was made in the neck, the trachea and esophagus were exposed, a breathing tube [polytetrafluoroethylene tubing; inner diameter (ID), $1.54 \mathrm{~mm}$; outer diameter (OD), $2.15 \mathrm{~mm}$; Angst and Pfister, Zurich, Switzerland) was inserted via a tracheotomy, and an intragastric cannula (polyethylene; ID, 1.40; OD, $2.0 \mathrm{~mm}$; B. Braun, Melsungen AG, Germany) was inserted via the esophagus. The left trunk of the vagus was gently separated from the carotid artery, and a silicon catheter (ID, $0.305 \mathrm{~mm}$; OD, $0.635 \mathrm{~mm}$; Ulrich AG, St. Gallen, Switzerland) was inserted $8 \mathrm{~cm}$, so that it ended near the junction of the celiac artery. Cannula placements were verified by dissection at the end of the experiment. To electrically isolate the nerve, a piece of Teflon tape (Angst and Pfister AG, Zurich, Switzerland) was placed under it and the site was filled with $37^{\circ} \mathrm{C}$ mineral oil (CVS Pharmacy, Woonsocket, RI). A small bundle of nerve fibers was peeled off and cut free from the main trunk, and the cut end was placed on a tungsten hook electrode (12 MÙ impedance; A-M Systems, Carlsborg, WA). A reference electrode was placed in the epineurium. Neural activity was sampled at $20 \mathrm{kHz}$ for computerized spike discrimination and frequency analysis (data interface model 401; Cambridge Electronic Design, Cambridge, MA). Fibers with obvious spontaneous activity were screened for sensitivity to gastric loads by comparing activity during a $30 \mathrm{~s}$ prestimulus baseline and a $30 \mathrm{~s}$ gastric load of $3 \mathrm{ml}$ of $37^{\circ} \mathrm{C}$ isotonic saline delivered at $\sim 0.5 \mathrm{ml} / \mathrm{s}$. The criterion for load-sensitive afferents was that gastric loads induced an at least twofold increase in spike frequency over the spontaneous discharge rate that lasted as long as the load was present and decreased to baseline when the load was withdrawn.

Once load-sensitive afferents were identified, two experiments were done. First, the effects of ghrelin in the absence of gastric loads were recorded in seven gastric load-sensitive fibers, each in a separate rat. At least $5 \mathrm{~min}$ after withdrawal of the gastric load, $10 \mathrm{nmol}$ ghrelin in $250 \mu \mathrm{l}$ of saline was infused into the intracarotid cannula over $15 \mathrm{~s}$. Neural activity was recorded for the two $30 \mathrm{~s}$ periods immediately before infusion and starting at infusion onset and for 60 s periods once each $5 \mathrm{~min}$ for $40 \mathrm{~min}$ after infusions. Then, another gastric load was administered to ensure the continued sensitivity of the fiber. Five minutes after this second load was withdrawn, 100 pmol CCK-8 was infused over $15 \mathrm{~s}$, and neural activity was recorded for the $30 \mathrm{~s}$ periods immediately before infusion, starting at infusion onset, and $30 \mathrm{~s}$ and $5 \mathrm{~min}$ thereafter.

Next, the phasic effects of ghrelin on the response to gastric loads of increasing volume were determined in eight other load-sensitive units, all but one in new rats. First, effects of intragastric loads of 1, 2, and $3 \mathrm{ml}$ of saline alone were recorded. Each load was infused at $0.5 \mathrm{ml} / \mathrm{s}$ and unit activity was recorded for $30 \mathrm{~s}$ starting at infusion onset. Interload intervals were $5 \mathrm{~min}$, and each load was preceded by a $30 \mathrm{~s}$ measurement of spontaneous activity. The same series was then repeated twice, with 10 nmol ghrelin infused together with intragastric loads during the first series and 100 pmol CCK- 8 during the second, each infused into the carotid artery as done previously.

Data analysis. The activities (spikes/s) of load-sensitive vagal afferent fibers were analyzed with within-subjects ANOVA followed by Tukey's honestly significant difference (HSD) tests. In the first experiment, the effects of ghrelin over the 10 sampling periods, the effects of CCK- 8 over four sampling periods, and the spontaneous activities measured before these two tests and the repeated load test were each analyzed with onefactor ANOVA; the effects of repeated gastric loads were analyzed with a two-factor ANOVA with time (before, during, and after load) and load number (first, second) as factors. In the second experiment, the ghrelin and CCK data were analyzed separately. First, a one-factor ANOVA was done of the spontaneous activity measures before each load and ghrelin treatment; then, because this did not reveal any differences across the experiment $\left(F_{(5,35)}=0.90 ; p=0.49\right)$, the three measures of spontaneous activity associated with each drug condition were collapsed into a single " $0 \mathrm{ml}$ load" mean, and the data were then analyzed with a two-factor ANOVA, with gastric load $(0,1,2$, and $3 \mathrm{ml})$ and ghrelin $(0,10 \mathrm{nmol})$ as factors. The same procedure was followed for the CCK data; two fibers with which spontaneous activity increased markedly during the CCK tests were not included.

\section{Results}

\section{SDA experiments}

SDA verification

In series 1 , three of 12 rats failed one of the two criteria for complete SDA and were eliminated from the data analysis; two failed the CCK criterion, and one failed the Flourogold retrograde labeling criterion. In series 2, 14 of the 29 rats failed the more stringent triple criterion for complete SDA; seven rats failed one of the three criteria and seven failed two (Table 1). Figure 1 
Table 1. Results of SDA verification in Series 2

\begin{tabular}{llll}
\hline Surgery performed & SDA & SHsda & $\begin{array}{l}\text { Intentionally } \\
\text { Incomplete SDA }\end{array}$ \\
\hline $\begin{array}{l}\text { Verified } \\
\text { Failed verification }\end{array}$ & 15 & 18 & 0 \\
$\begin{array}{l}\text { Criteria failed } \\
\quad 14\end{array}$ & 4 \\
$\quad$ CCK & $4(1)$ & \\
HRP & $6(1)$ & 4 \\
$\quad$ Flourogold & $11(5)$ & 4 \\
\hline
\end{tabular}

Data are number of rats failing each criterion, with number of rats failing only that criterion given in parentheses (7 rats failed two criteria; no rat failed all three). The (CK exclusion criterion was that intraperitoneal injection of 4 $\mu \mathrm{g} / \mathrm{kg}$ CCK-8 inhibits food intake > 30\%; HRP criterion was based on anterograde labeling of the NTS; fluorogold criterion was based on retrograde labeling of the DMX (see Materials and Methods for details). The CCK test was not done in intentionally incomplete SDA rats.

shows representative subpostremal DVC sections from SHsda, incomplete SDA and complete SDA rats. Finally, two of the intentionally incomplete SDA rats prepared in series 2 showed low levels of NTS and DMX staining similar to the SDA rats that were deemed incomplete, and two showed intense staining more similar to the SHsda rats (data not shown).

\section{Ghrelin-induced eating}

The stimulatory effects of IP injection of ghrelin on eating were indistinguishable in SHsda and SDA rats at each ghrelin dose and time point. Specifically, the post hoc analysis revealed no differences in the crucial comparison [(SHsda ghrelin - SHsda vehicle) vs (SDA ghrelin - SDA vehicle)] after any ghrelin dose at any time. In series 1 , food intake was significantly increased after injection of either 20 or $40 \mu \mathrm{g} / \mathrm{kg}$ ghrelin at each of the three measurements (range of the six main effects of ghrelin, $F_{(1,19)}=$ 8.44-25.93; $p$ values $<0.01$ ) (Fig. 2). After $40 \mu \mathrm{g} / \mathrm{kg}$ ghrelin, neither the main effects of SDA nor the interactions of ghrelin $\times$ SDA approached significance at 30 and $60 \mathrm{~min}$ (range of six tests, $F_{(1,19)}=0.00-1.66 ; p$ values $\left.=0.21-0.98\right)$. After $20 \mu \mathrm{g} / \mathrm{kg}$ ghrelin, the main effects of surgery were significant at each time (range of three tests, $F_{(1,19)}=5.97-21.21$; $p$ values $<0.03-0.001$ ). These effects of surgery were caused by larger intakes in the SHsda rats; however, the increases were very similar after the saline and ghrelin injection and none of the interactions of ghrelin $\times$ SDA approached significance (range of three tests, $F_{(1,19)}=0.00-0.04$; $p$ values $=0.99-0.84)$. In contrast to the reliable eatingstimulatory effects of 20 and $40 \mu \mathrm{g} / \mathrm{kg}$ ghrelin, injection of 10 $\mu \mathrm{g} / \mathrm{kg}$ ghrelin did not reliably affect food intake (range of ghrelin main effects and ghrelin $\times$ SDA interaction effects, $F_{(1,19)}=$ $0.01-2.71 ; p$ values $=0.94-0.12$ ) (Fig. 2).

In series 2 , the main effects of ghrelin treatment were highly significant after both 30 and $60 \mathrm{~min}\left(F_{(1,31)}=28.31\right.$ and $13.11 ; p$ values $<0.001$ ), but neither the main effects of SDA nor the interaction effects of ghrelin $\times$ SDA approached significance (range of the four tests, $F_{(1,31)}=0.04-0.55 ; p$ values $=0.83-$ $0.47)$. Similarly, after $120 \mathrm{~min}$, ghrelin stimulated eating in both groups $(Z=2.70$ and $2.41, p<0.01$ and 0.02 , for SHsda and SDA rats, respectively), and there was no difference between the groups $(Z=0.27 ; p=0.79)$ (Fig. 3$)$.

\section{TVX}

TVX verification

One of nine rats failed our criteria for complete TVX because of a positive response in the CCK test. Figure 4 shows representative subpostremal DVC sections from SHtvx and TVX rats.

\section{Ghrelin-induced eating}

The stimulatory effect of IP injection of $40 \mu \mathrm{g} / \mathrm{kg}$ ghrelin on eating was indistinguishable in SHtvx and TVX rats at each time

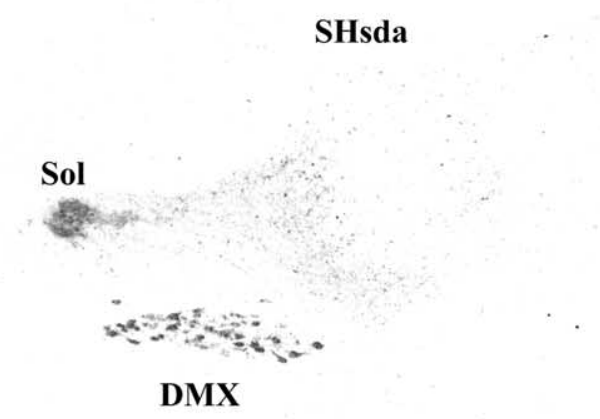

$200 \mu \mathrm{m}$

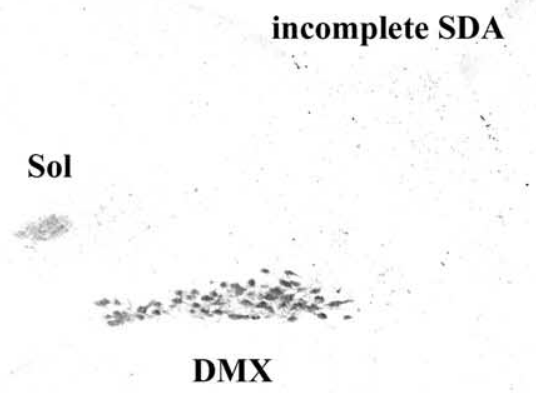

$200 \mu \mathrm{m}$

complete SDA

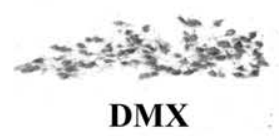

$\mu \mathrm{m}$

Figure 1. Inverted dark-field photomicrographs of representative sections of the subpostremal dorsal vagal complex from rats with SHsda, intentionally incomplete SDA, and complete SDA. All rats showed retrograde labeling of vagal motor neurons in the left DMX. Anterograde labeling of vagal afferents in the overlying left NTS was absent after SDA. Sol, Solitary tract. Wheat germ agglutinin-HRP $(2 \%)$ in saline $(1.5 \mu l)$ was pressure injected into the left nodose ganglion using a micromanipulator. See Materials and Methods for additional details.

point (Fig. 5). The main effects of ghrelin treatment were highly significant at each time point $\left(F_{(1,15)}=16.43,14.96\right.$, and $8.71 ; p$ values $<0.001,0.002$, and 0.01 , respectively), but neither the main effects of TVX nor the interaction effects of ghrelin $\times$ TVX approached significance (range of the six tests, $F_{(1,15)}=0.00-$ $0.84 ; p$ values $=0.99-0.37)$. 


\section{$10 \mu \mathrm{g} / \mathrm{kg} \mathrm{BW}$ Ghrelin}

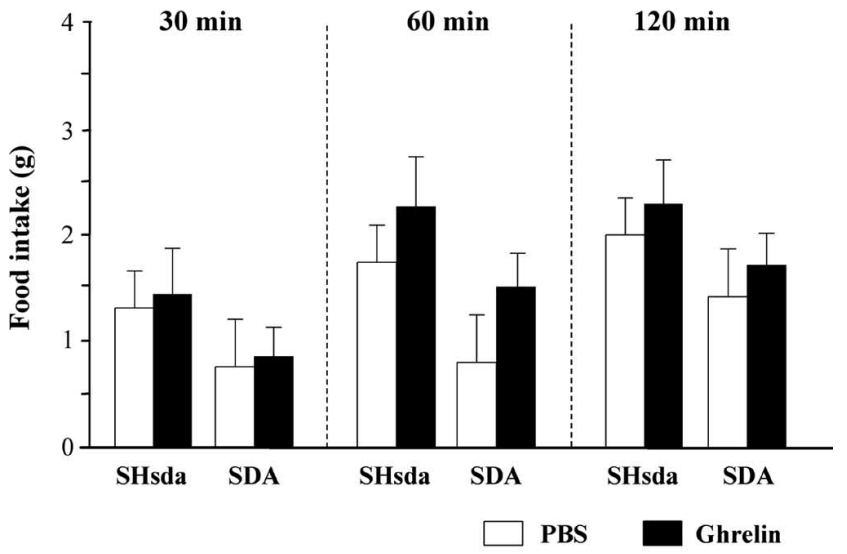

$20 \mu \mathrm{g} / \mathrm{kg}$ BW Ghrelin

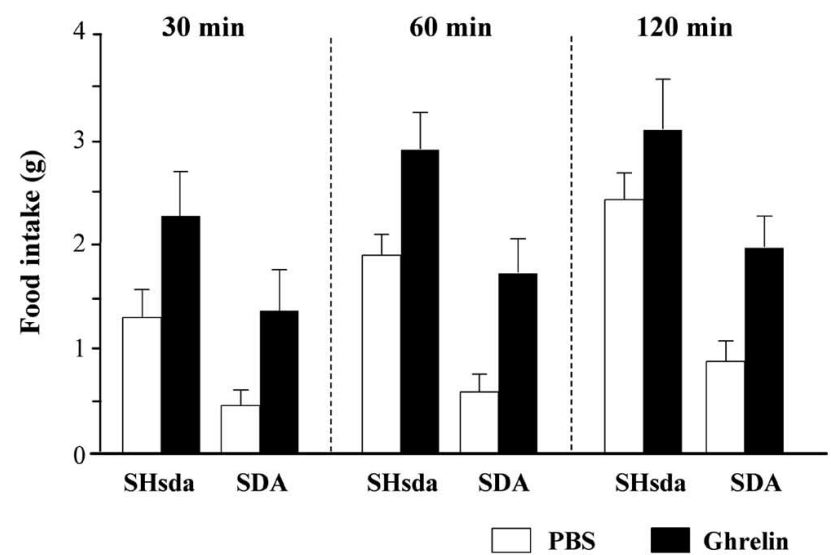

$40 \mu \mathrm{g} / \mathrm{kg}$ BW Ghrelin

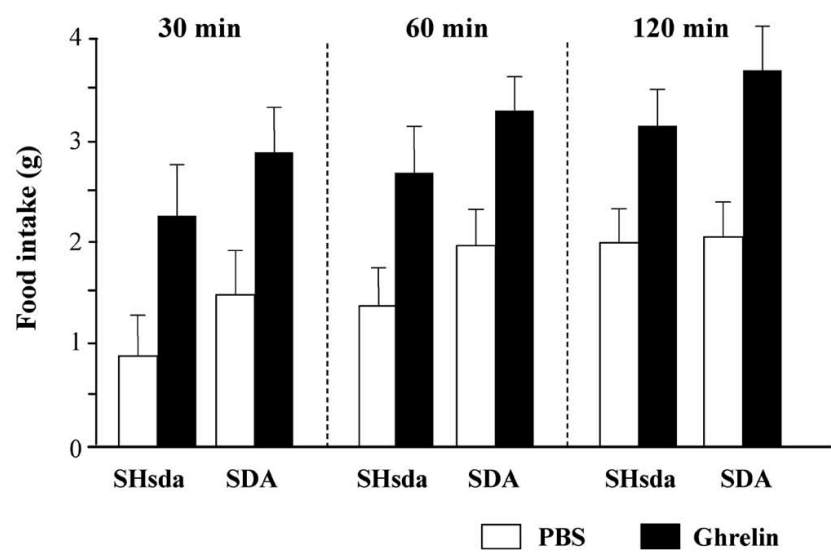

Figure 2. In series 1,20 and $40 \mu \mathrm{g} / \mathrm{kg}$ BW ghrelin increased food intake in rats with verified complete SDA and SHsda at each time point measured. BW ghrelin (10 $\mu \mathrm{g} / \mathrm{kg})$ failed to reliably stimulate eating in either group. Post hoc (Bonferroni-Holm): for $20 \mu \mathrm{g} / \mathrm{kg}$ ghrelin, ghrelin PBS difference, $p<0.05$ for each time and group; for $40 \mu \mathrm{g} / \mathrm{kg}$ ghrelin, $p<0.01$ for each time and group; differences in eating-stimulatory effect of 20 or $40 \mu \mathrm{g} / \mathrm{kg}$ BW ghrelin between SDA and SHsda rats; not significant. Error bars represent means \pm SE of 12 SHsda and nine SDA rats. See Results for additional details.

\section{Electrophysiology}

Ghrelin alone did not reliably affect the mean activity of the seven gastric load-sensitive vagal afferents tested $\left(F_{(9,54)}=1.09 ; p=\right.$ 0.38 ) (Fig. 6). Ghrelin did appear to elicit a phasic increase in

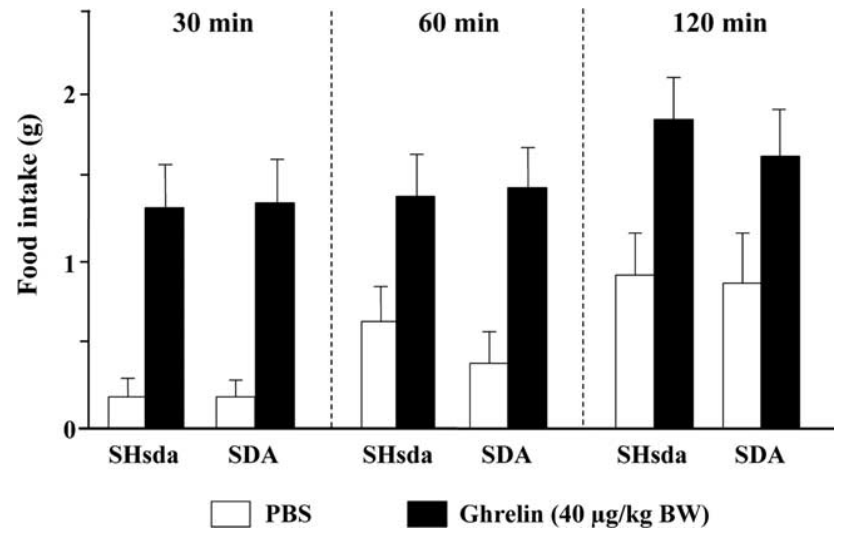

Figure 3. In series $2,40 \mu \mathrm{g} / \mathrm{kg} \mathrm{BW}$ ghrelin again increased food intake similarly in rats with verified complete SDA and SHsda at each time point measured. Post hoc (Bonferroni-Holm): 30 $\min , p<0.001$ for SDA and SHsda; 60 min, $p<0.05$ for SDA and SHsda; 120 min, $p<0.02$ for SDA and $p<0.01$ for SHsda; differences in eating-stimulatory effect of ghrelin between SDA and SHsda rats, not significant. Error bars represent means \pm SE of 17 SHsda and 15 SDA rats. See Results for additional details.

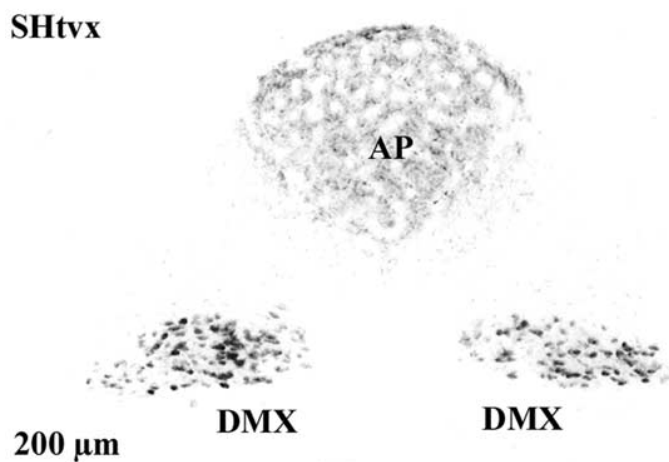

TVX

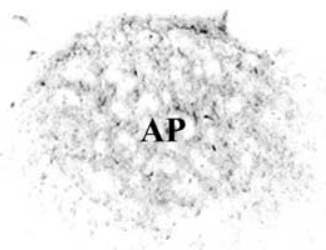

$200 \mu \mathrm{m}$

Figure 4. Inverted fluorescence photomicrographs of representative sections of the subpostremal dorsal vagal complex from rats with sham vagotomy (SHtvx) or complete subdiaphragmatic vagotomy (TVX). SHtvx rats showed retrograde labeling of vagal motor neurons in the DMX; TVX rats did not. Each rat was intraperitoneally injected with $2 \mathrm{mg}$ of fluorogold (Fluorochrome) in $1 \mathrm{ml}$ of saline. See Materials and Methods for additional details.

activity during the 30 s period during and after the infusion in two fibers; interestingly, these were the two fibers with the highest spontaneous activity (fibers a and $\mathrm{b}$ ). After this phasic response, the activity of fiber a sank well below the basal level for the re- 


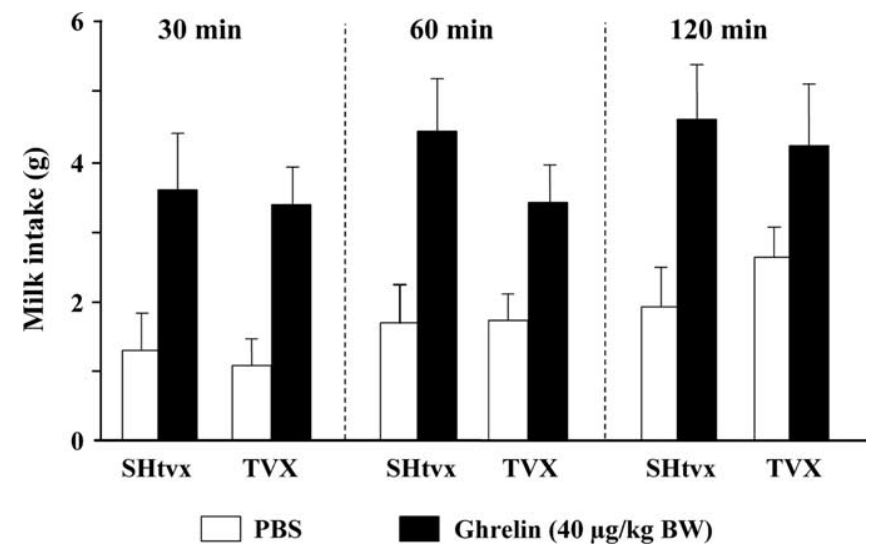

Figure 5. BW ghrelin $(40 \mu \mathrm{g} / \mathrm{kg})$ increased food intake similarly in rats with verified complete subdiaphragmatic vagotomy (TVX) and sham vagotomy (SHtvx) at each time point measured. Post hoc comparisons (Bonferroni-Holm): ghrelin - PBS difference at $30 \mathrm{~min}, p<0.02$ for both TVX and SHtvx; at 60 and 120 min, $p<0.05$ for both TVX and SHtvx; differences in eating-stimulatory effect of ghrelin between TVX and SHtvx rats, not significant. Error bars represent means \pm SE of nine SHtvx and eight TVX rats. See Results for additional details.

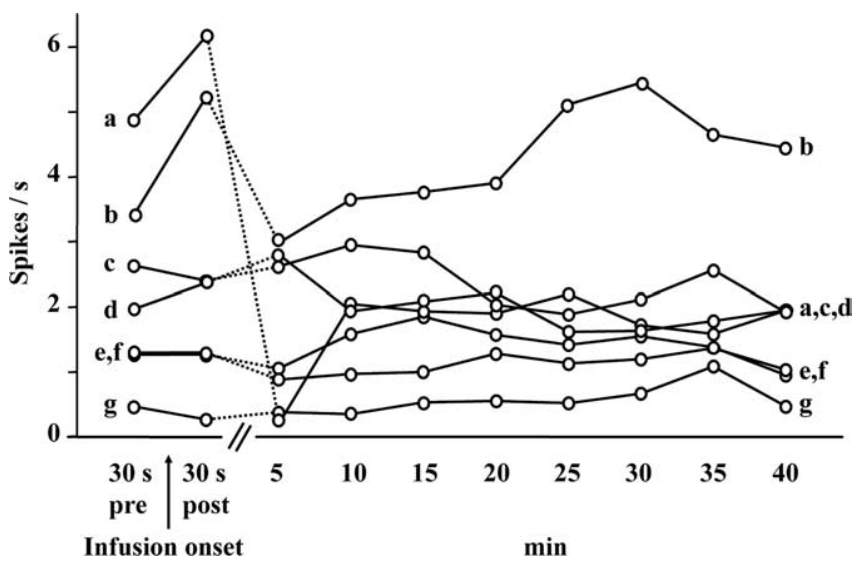

Figure 6. Intracarotid infusion of ghrelin ( $10 \mathrm{nmol}$ in $250 \mu$ l saline at $1 \mathrm{ml} / \mathrm{min}$ ) did not reliably affect the activity of gastric load-sensitive vagal afferents tested without gastric loads. Lines represent results from each of seven fibers recorded in seven different rats $(a-g)$. Neural activity was recorded for the 30 s periods immediately before infusion and starting at infusion onset (preinfusion and postinfusion onset) and for 60 s periods once each 5 min for 40 min after infusions. See Results for additional details.

mainder of the test, whereas fiber b subsequently returned to baseline by $10 \mathrm{~min}$ postinfusion and then rose above baseline during the latter part of the $40 \mathrm{~min}$.

The average spontaneous activities of fibers and gastric loadstimulated activities were very stable. The two gastric loads each significantly increased activity (to $158 \pm 33$ and $140 \pm 28$ spikes/ $100 \mathrm{~ms}$, respectively; $\left.F_{(2,12)}=18.36 ; p<0.001\right)$, but the two increases were not significantly different from each other, and there were no significant differences in the preload and postload baselines (range, $11 \pm 7$ to $24 \pm 6$ spikes/100 ms). Similarly, the units also emitted a vigorous phasic response to CCK-8 infusion $\left(F_{(3,18)}=25.80 ; p<0.001\right)$ but recovered to baseline in $\sim 5 \mathrm{~min}$ (data not shown).

In the second experiment, ghrelin failed to affect the response of load-sensitive vagal afferents to increasing load volumes (Fig. $7 A$, left). Gastric loads volume-dependently increased vagal afferent activity $\left(F_{(3,21)}=11.28 ; p<0.001\right)$, but there was no effect of ghrelin $\left(F_{(1,7)}=0.01 ; p=0.92\right)$ or interaction effect of ghrelin and load. Recordings from representative individual fibers are

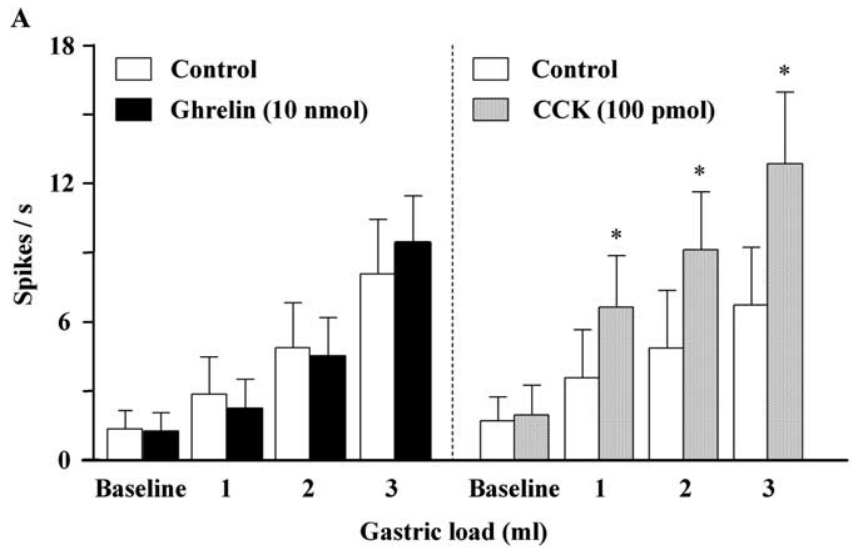

B
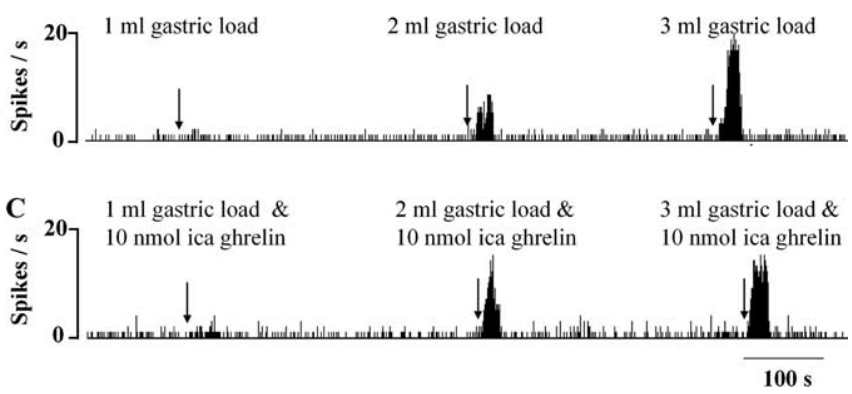

Figure 7. A, Gastric loads volume-dependently increased single-unit vagal afferent activity and intracarotid infusion of ghrelin ( $10 \mathrm{nmol}$ in $250 \mu \mathrm{l}$ of saline at $1 \mathrm{ml} / \mathrm{min}$ ) did not reliably affect this response (left). In contrast, CCK-8 (100 pmol) infusion significantly increased the response to gastric load (right). Post hoc comparisons (Tukey's HSD): effects of each gastric load alone (except $1 \mathrm{ml}$ in left panel), $p<0.05$; all ghrelin-control differences are not significant; CCK-control differences after one to three gastric loads, ${ }^{*} p<0.05$. B, Activity of a representative gastric load-sensitive vagal afferent fiber in response to gastric loads of 1,2 , and $3 \mathrm{ml}$ of saline (infusion at arrows). C, Activity of a representative gastric load-sensitive vagal afferent fiber in response to gastric loads of 1,2 , and $3 \mathrm{ml}$ of saline in combination with intracarotid (ica) infusions of $10 \mathrm{nmol}$ ghrelin (both infusions at arrows).

shown in Figure 7, $B$ and $C$. In contrast, as reported previously (Schwartz et al., 1991, 1993; Moran et al., 1997), CCK-8 infusion markedly increased the response of load-sensitive vagal afferents to increasing load volumes (Fig. $7 A$, right). The main effects of load $\left(F_{(3,15)}=15.95 ; p<0.001\right)$ and of CCK $\left(F_{(1,5)}=8.96 ; p<\right.$ $0.03)$ and their interaction $\left(F_{(3,15)}=3.78 ; p<0.04\right)$ were all significant.

\section{Discussion}

Ghrelin has been hypothesized to have two roles in the physiological control of eating and energy balance (Kojima et al., 1999; Geary, 2004; van der Lely et al., 2004; Kojima and Kangawa, 2005; Williams and Cummings, 2005). First, ghrelin may be a "meal control signal" (Strader and Woods, 2005) because in both animals and humans, plasma levels of ghrelin increase before individual meals and acute ghrelin administration stimulates eating. Second, ghrelin may be an "adiposity signal" because its basal plasma level correlates with adiposity and, in rats and mice, longer-term administration of ghrelin increases body weight (Tschop et al., 2000; Nakazato et al., 2001).

Where ghrelin acts to stimulate eating is uncertain. GHS-R1a mRNA is present in numerous brain sites (Zigman et al., 2006), and ghrelin administration into four of them, Arc, PVN, VTA, and DVC, has been reported to stimulate eating (Wren et al., 2001a; Bagnasco et al., 2003; Cowley et al., 2003; Faulconbridge et 
al., 2003; Olszewski et al., 2003; Currie et al., 2005; Naleid et al., 2005). In addition, one peripheral site, gastric vagal afferents (Asakawa et al., 2001; Date et al., 2002, 2005; le Roux et al., 2005), has been proposed. The results of surgical vagotomy reported here do not support any necessary role of abdominal vagal afferents in the acute eating-stimulatory effect of intraperitoneally injected ghrelin in rats, suggesting that this effect arises from stimulation of brain, rather than peripheral, GHS-R1a.

Neither TVX nor SDA diminished the eating-stimulatory effect of ghrelin. This is the first report of the effect of peripherally administered ghrelin in SDA rats. We used SDA because it eliminates abdominal vagal afferents while sparing approximately half of the vagal motor neurons (Norgren and Smith, 1994; Walls et al., 1995; Moran et al., 1997; Schwartz et al., 1997). Therefore, SDA has fewer side effects that might interfere with the normal control of food intake and affect the results of ghrelin challenges. In rats and humans, gastric vagotomy often produces gastrointestinal motor and secretory dysfunction, anorexia, and malnutrition (Kraly et al., 1986; King et al., 1987). Also, we attempted to maximize the validity of our tests by including only data from animals that passed stringent functional and histological criteria for complete lesions and by using two groups of independently operated, tested, and verified animals. Previous reports have not included either type of verification (Asakawa et al., 2001; Date et al., 2002, 2005). The failure of SDA to block ghrelin-induced eating in animals with conservatively verified lesions strongly indicates that abdominal vagal afferents were not involved in ghrelin-induced eating under our conditions. Furthermore, because we saw exactly the same pattern of data both after a high (40 $\mu \mathrm{g} / \mathrm{kg})$ and a near threshold $(20 \mu \mathrm{g} / \mathrm{kg})$ ghrelin dose, the failure of SDA to block ghrelin-induced eating was not an artifact of testing only a single, supermaximal dose.

One hypothesis that could reconcile our negative effect of SDA on ghrelin-induced eating with the positive effects of gastric or TVX reported previously (Asakawa et al., 2001; Date et al., 2002, 2005) is that the complete efferent gastric vagal lesions of the latter methods unmask a role of vagal afferents. For example, as vagal efferents participate in the control of ghrelin secretion (Date et al., 2002; Arosio et al., 2004; Williams and Cummings, 2005), vagal efferent lesions may alter ghrelin tone in a way that affects vagal afferent responsivity. We therefore re-examined the effect of TVX on ghrelin-induced eating, again attempting to minimize the nonspecific effects of the lesion by careful postoperative care, verifying the animals' ability to eat nearly normally before testing, and verifying the lesions functionally and histologically. In these tests, ghrelin stimulated eating normally in TVX rats. We conclude, therefore, that abdominal vagal afferents are not necessary for the eating-stimulatory effect of ghrelin under our conditions.

Our data contrast with reports that vagal lesions reduce the eating-stimulatory effect of ghrelin in mice, rats, and humans (Asakawa et al., 2001; Date et al., 2002, 2005; le Roux et al., 2005). What accounts for this discrepancy is unclear. Of course, species and even strain differences or just slightly different test conditions may be involved. Perhaps it is relevant that in the other rat study (Date et al., 2002), ghrelin was injected intravenously rather than intraperitoneally. Two other methodological differences may have been important. First, as we verified our vagotomies very conservatively, with both functional and histological tests, we do not think our lesions were incomplete. Second, our animals were in good physical condition at the time of the tests and were clearly capable of consuming large test meals. It is unclear that this was the case in previous reports. In the report of the effects of TVX and of gastric vagotomies in rats by Date et al. (2002), tests began only 1 week postoperatively and $2 \mathrm{~h}$ food intakes were only $\sim 0.2 \mathrm{~g}$ even after saline injections. Body weights were not reported. Thus, the animals' capacity to eat during the tests was uncertain. It should be noted, however, that in a subsequent test that apparently used the same animals, baselines were similarly low and intracerebroventricular injection of ghrelin did stimulate eating. In the tests of Asakawa et al. (2001), mice were vagotomized $4 \mathrm{~d}$ before testing. Although vagotomized mice ate during the $4 \mathrm{~h}$ test, their intakes were only $\sim 60 \%$ that of controls, and, again, the animals' body weights were not reported. Finally, the test of humans with vagal lesions and partial or total gastrectomy by le Roux et al. (2005) had no vagally intact control group, and the test meal size during saline infusions was $\sim 40 \%$ less than in a similarly designed study of nonvagotomized subjects (Wren et al., 2001b). Thus, side effects might explain the previously reported blockade of the eating-stimulatory effect of ghrelin by surgical vagotomies. Surgical side effects, however, cannot explain the lack of eating-stimulatory effect of ghrelin following capsaicin lesions of small, unmyelinated afferents (Date et al., 2002). Unlike surgical vagotomy, however, capsaicin spares myelinated afferents and lesions more nonvagal (i.e., spinal visceral) afferents. Thus, one interpretation accommodating the SDA and capsaicin data is that unmyelinated spinal visceral afferents mediate the eating-stimulatory effect of ghrelin. This hypothesis deserves a direct test.

Another hypothesis that fits our data is that peripherally administered ghrelin acts in the brain to stimulate eating. Ghrelin administration into four brain sites containing GHS-1Ra, Arc, PVN, VTA, and DVC, has been reported to stimulate eating (Wren et al., 2001a; Bagnasco et al., 2003; Cowley et al., 2003; Faulconbridge et al., 2003; Olszewski et al., 2003; Currie et al., 2005; Naleid et al., 2005), and several other brain sites implicated in the control of eating also contain GHS-1Ra (Zigman et al., 2006). It remains unclear, however, whether circulating ghrelin reaches any of these brain sites in sufficient amounts to explain the eating-stimulatory actions of either endogenous or peripherally administered ghrelin (Geary, 2004). Indeed, mice appear to possess a specific brain-to-blood active transporter for ghrelin but to lack a blood-to-brain transporter (Banks et al., 2002).

Peripheral ghrelin administration also affects the activity of vagal afferents in rats. Both Asakawa et al. (2001) and Date et al. $(2002,2005)$ reported that injections of $0.1 \mathrm{pmol}$ to $1.5 \mathrm{nmol}$ ghrelin into the inferior vena cava decreased the multiunit activity in the cut gastric branch of anesthetized rats. The inhibition developed slowly over several minutes and lasted over $1 \mathrm{~h}$. We attempted to extend these data by characterizing the electrophysiological response of single gastric load-sensitive vagal afferent fibers to intravenous injection of $10 \mathrm{nmol}$ ghrelin. We investigated afferents that were stimulated by moderate-volume gastric loads because this allows for identification of a substantial proportion of the abdominal vagal afferents in the cervical vagal trunk and because reports of synergistic interactions in the responses of these fibers to simultaneous gastric loading and either CCK or intraduodenal nutrient infusion indicate that many of them integrate stimuli of different modalities from different sites (Schwartz et al., 1991, 1993; Moran et al., 1997). The activities of these single, gastric load-sensitive fibers differed in several ways from the results of previous investigations of the effect of ghrelin on multiunit gastric vagal afferent activity (Asakawa et al., 2001; Date et al., 2002, 2005). First, only one of 15 fibers recorded from displayed the lasting decrease in activity after ghrelin injection that was reported previously (Asakawa et al., 2001; Date et al., 
2002, 2005). Second, one fiber displayed a lasting increase in activity between $\sim 15$ and $40 \mathrm{~min}$ after ghrelin injection. Third, the two fibers described above also displayed brief, $\sim 50 \%$ increases in activity during the first $30 \mathrm{~s}$ after injection. And fourth, overall electrophysiological activity did not change in response to intravenous ghrelin injection either in the presence or absence of gastric loads. Thus, ghrelin may have both inhibitory and excitatory effects on subsets of gastric load-sensitive vagal afferents. Because these responses vary qualitatively and occur in only a small minority of gastric load-sensitive vagal afferents, a sophisticated across-fiber analysis would be needed to establish what ghrelin-related information they encode. Because vagal afferents do not appear necessary for the eating-stimulatory effect of IP ghrelin, ghrelin-related electrophysiological activity probably has other functions, perhaps in the vagal control of ghrelin secretion (Moran et al., 1997; Williams et al., 2003; Williams and Cummings, 2005).

In conclusion, the major result of these studies was that IP injections of ghrelin stimulated eating as effectively in rats with verified complete SDA or TVX as in sham-operated control rats, indicating that abdominal vagal afferents are not required for the acute eating-stimulatory effect of peripheral ghrelin.

\section{References}

Arnold M, Mura A, Geary N, Langhans W (2004) Subdiaphragmatic vagal afferents are not necessary for the feeding-stimulatory effect of intraperiotoneally administered ghrelin. Soc Neurosci Abstr 30:194.8.

Arosio M, Ronchi CL, Beck-Peccoz P, Gebbia C, Giavoli C, Cappiello V, Conte D, Peracchi M (2004) Effects of modified sham feeding on ghrelin levels in healthy human subjects. J Clin Endocrinol Metab 89:5101-5104.

Asakawa A, Inui A, Kaga T, Yuzuriha H, Nagata T, Ueno N, Makino S, Fujimiya M, Niijima A, Fujino MA, Kasuga M (2001) Ghrelin is an appetite-stimulatory signal from stomach with structural resemblance to motilin. Gastroenterology 120:337-345.

Asakawa A, Inui A, Kaga T, Katsuura G, Fujimiya M, Fujino MA, Kasuga M (2003) Antagonism of ghrelin receptor reduces food intake and body weight gain in mice. Gut 52:947-952.

Bagnasco M, Tulipano G, Melis MR, Argiolas A, Cocchi D, Muller EE (2003) Endogenous ghrelin is an orexigenic peptide acting in the arcuate nucleus in response to fasting. Regul Pept 111:161-167.

Banks WA, Tschop M, Robinson SM, Heiman ML (2002) Extent and direction of ghrelin transport across the blood-brain barrier is determined by its unique primary structure. J Pharmacol Exp Ther 302:822-827.

Cowley MA, Smith RG, Diano S, Tschop M, Pronchuk N, Grove KL, Strasburger CJ, Bidlingmaier M, Esterman M, Heiman ML, Garcia-Segura LM, Nillni EA, Mendez P, Low MJ, Sotonyi P, Friedman JM, Liu H, Pinto S, Colmers WF, Cone RD, Horvath TL (2003) The distribution and mechanism of action of ghrelin in the CNS demonstrates a novel hypothalamic circuit regulating energy homeostasis. Neuron 37:649-661.

Currie PJ, Mirza A, Fuld R, Park D, Vasselli JR (2005) Ghrelin is an orexigenic and metabolic signaling peptide in the arcuate and paraventricular nuclei. Am J Physiol Regul Integr Comp Physiol 289:R353-R358.

Date Y, Murakami N, Toshinai K, Matsukura S, Niijima A, Matsuo H, Kangawa K, Nakazato M (2002) The role of the gastric afferent vagal nerve in ghrelin-induced feeding and growth hormone secretion in rats. Gastroenterology 123:1120-1128.

Date Y, Toshinai K, Koda S, Miyazato M, Shimbara T, Tsuruta T, Niijima A, Kangawa K, Nakazato M (2005) Peripheral interaction of ghrelin with cholecystokinin on feeding regulation. Endocrinology 146:3518-3525.

Faulconbridge LF, Cummings DE, Kaplan JM, Grill HJ (2003) Hyperphagic effects of brainstem ghrelin administration. Diabetes 52:2260-2265.

Geary N (2004) Endocrine controls of eating: CCK, leptin, and ghrelin. Physiol Behav 81:719-733.

Gibson AR, Hansma DI, Houk JC, Robinson FR (1984) A sensitive low artifact TMB procedure for the demonstration of WGA-HRP in the CNS. Brain Res 298:235-241.

Hamilton RB, Norgren R (1984) Central projections of gustatory nerves in the rat. J Comp Neurol 222:560-577.
Holms (1979) A simple sequentially rejective multiple test procedure. Scand J Statist 6:65-70.

Howard AD, Feighner SD, Cully DF, Arena JP, Liberator PA, Rosenblum CI, Hamelin M, Hreniuk DL, Palyha OC, Anderson J, Paress PS, Diaz C, Chou M, Liu KK, McKee KK, Pong SS, Chaung LY, Elbrecht A, Dashkevicz M, Heavens R, et al. (1996) A receptor in pituitary and hypothalamus that functions in growth hormone release. Science 273:974-977.

King RM, Pairolero PC, Trastek VF, Payne WS, Bernatz PE (1987) Ivor Lewis esophagogastrectomy for carcinoma of the esophagus: early and late functional results. Ann Thorac Surg 44:119-122.

Kobelt P, Tebbe JJ, Tjandra I, Stengel A, Bae HG, Andresen V, van dV, I, Veh RW, Werner CR, Klapp BF, Wiedenmann B, Wang L, Tache Y, Monnikes $\mathrm{H}$ (2005) CCK inhibits the orexigenic effect of peripheral ghrelin. Am J Physiol Regul Integr Comp Physiol 288:R751-R758.

Kojima M, Kangawa K (2005) Ghrelin: structure and function. Physiol Rev 85:495-522.

Kojima M, Hosoda H, Date Y, Nakazato M, Matsuo H, Kangawa K (1999) Ghrelin is a growth-hormone-releasing acylated peptide from stomach. Nature 402:656-660.

Kraly FS, Jerome C, Smith GP (1986) Specific postoperative syndromes after total and selective vagotomies in the rat. Appetite 7:1-17.

le Roux CW, Neary NM, Halsey TJ, Small CJ, Martinez-Isla AM, Ghatei MA, Theodorou NA, Bloom SR (2005) Ghrelin does not stimulate food intake in patients with surgical procedures involving vagotomy. J Clin Endocrinol Metab 90:4521-4524.

Le Sauter J, Geary N (1990) Redundant vagal mediation of the synergistic satiety effect of pancreatic glucagon and cholecystokinin in sham feeding rats. J Auton Nerv Syst 30:13-22.

Mathis C, Moran TH, Schwartz GJ (1998) Load-sensitive rat gastric vagal afferents encode volume but not gastric nutrients. Am J Physiol 274:R280-R286.

Moran TH, Baldessarini AR, Salorio CF, Lowery T, Schwartz GJ (1997) Vagal afferent and efferent contributions to the inhibition of food intake by cholecystokinin. Am J Physiol 272:R1245-R1251.

Mura A, Arnold M, Langhans W (2004) The effect of ghrelin on gastric vagal nerve afferents activity in rats. Appetite 42:387.

Murakami N, Hayashida T, Kuroiwa T, Nakahara K, Ida T, Mondal MS, Nakazato M, Kojima M, Kangawa K (2002) Role for central ghrelin in food intake and secretion profile of stomach ghrelin in rats. J Endocrinol 174:283-288.

Nakazato M, Murakami N, Date Y, Kojima M, Matsuo H, Kangawa K, Matsukura S (2001) A role for ghrelin in the central regulation of feeding. Nature 409:194-198.

Naleid AM, Grace MK, Cummings DE, Levine AS (2005) Ghrelin induces feeding in the mesolimbic reward pathway between the ventral tegmental area and the nucleus accumbens. Peptides 26:2274-2279.

Norgren R, Smith GP (1988) Central distribution of subdiaphragmatic vagal branches in the rat. J Comp Neurol 273:207-223.

Norgren R, Smith GP (1994) A method for selective section of vagal afferent or efferent axons in the rat. Am J Physiol 267:R1136-R1141.

Olszewski PK, Grace MK, Billington CJ, Levine AS (2003) Hypothalamic paraventricular injections of ghrelin: effect on feeding and c-Fos immunoreactivity. Peptides 24:919-923.

Phillips RJ, Baronowsky EA, Powley TL (2000) Regenerating vagal afferents reinnervate gastrointestinal tract smooth muscle of the rat. J Comp Neurol 421:325-346.

Powley TL, Fox EA, Berthoud HR (1987) Retrograde tracer technique for assessment of selective and total subdiaphragmatic vagotomies. Am J Physiol 253:R361-R370.

Schmid DA, Held K, Ising M, Uhr M, Weikel JC, Steiger A (2005) Ghrelin stimulates appetite, imagination of food, GH, ACTH, and cortisol, but does not affect leptin in normal controls. Neuropsychopharmacology 30:1187-1192.

Schwartz GJ, McHugh PR, Moran TH (1991) Integration of vagal afferent responses to gastric loads and cholecystokinin in rats. Am J Physiol 261:R64-R69.

Schwartz GJ, McHugh PR, Moran TH (1993) Gastric loads and cholecystokinin synergistically stimulate rat gastric vagal afferents. Am J Physiol 265:R872-R876. 
Schwartz GJ, Plata-Salaman CR, Langhans W (1997) Subdiaphragmatic vagal deafferentation fails to block feeding-suppressive effects of LPS and IL-1 beta in rats. Am J Physiol 273:R1193-R1198.

Smith GP, Jerome C, Cushin BJ, Eterno R, Simansky KJ (1981) Abdominal vagotomy blocks the satiety effect of cholecystokinin in the rat. Science 213:1036-1037.

Smith GP, Jerome C, Norgren R (1985) Afferent axons in abdominal vagus mediate satiety effect of cholecystokinin in rats. Am J Physiol 249:R638-R641.

Strader AD, Woods SC (2005) Gastorintestinal hormones and food intake. Gastroenterol 128:175-191.

Tschop M, Smiley DL, Heiman ML (2000) Ghrelin induces adiposity in rodents. Nature 407:908-913.

van der Lely AJ, Tschop M, Heiman ML, Ghigo E (2004) Biological, physiological, pathophysiological, and pharmacological aspects of ghrelin. Endocr Rev 25:426-457.

Walls EK, Wang FB, Holst MC, Phillips RJ, Voreis JS, Perkins AR, Pollard LE,
Powley TL (1995) Selective vagal rhizotomies: a new dorsal surgical approach used for intestinal deafferentations. Am J Physiol 269: R1279-R1288.

Williams DL, Cummings DE (2005) Regulation of ghrelin in physiologic and pathophysiologic states. J Nutr 135:1320-1325.

Williams DL, Grill HJ, Cummings DE, Kaplan JM (2003) Vagotomy dissociates short- and long-term controls of circulating ghrelin. Endocrinology 144:5184-5187.

Wren AM, Small CJ, Abbott CR, Dhillo WS, Seal LJ, Cohen MA, Batterham RL, Taheri S, Stanley SA, Ghatei MA, Bloom SR (2001a) Ghrelin causes hyperphagia and obesity in rats. Diabetes 50:2540-2547.

Wren AM, Seal LJ, Cohen MA, Brynes AE, Frost GS, Murphy KG, Dhillo WS, Ghatei MA, Bloom SR (2001b) Ghrelin enhances appetite and increases food intake in humans. J Clin Endocrinol Metab 86:5992.

Zigman JM, Jones JE, Lee CE, Saper CB, Elmquist JK (2006) Expression of ghrelin receptor mRNA in the rat and the mouse brain. J Comp Neurol 494:528-548. 